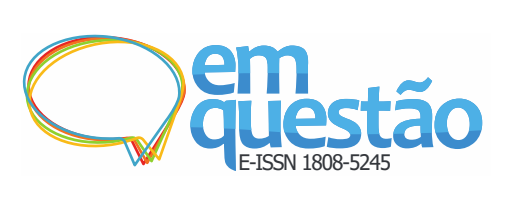

\title{
Políticas públicas de informação: um olhar para o acesso à Internet e para a inclusão digital no cenário brasileiro
}

\author{
Angela Halen Claro Franco \\ Doutora, Fundação Escola de Sociologia e Política de São Paulo, São Paulo, SP, Brasil; \\ Superintendência do Patrimônio da União em São Paulo, São Paulo, SP, Brasil; \\ angelahalen@gmail.com; ORCID: https://orcid.org/0000-0001-9693-9458
}

\begin{abstract}
Resumo: Tem como objetivo identificar o cenário recente das ações do Governo Federal voltadas para a democratização do acesso à Internet no contexto nacional. Optou-se como procedimento metodológico pela pesquisa de base, de caráter descritivo e delineamento bibliográfico e documental, considerando as ações empreendidas pelo Governo Federal de 2010 a 2019. A análise foi conduzida pela abordagem qualitativa. Foram identificadas dez inciativas principais que dialogam com a ampliação do acesso à Internet, sendo a mais antiga o Programa Nacional de Banda Larga e as mais recentes as Políticas Públicas de Telecomunicações e o Novo Marco Legal das Telecomunicações. Os principais pontos sobre a inclusão digital observados nas iniciativas identificadas são a infraestrutura para acesso à Internet e a educação para uso das tecnologias da informação e comunicação. Essas perspectivas apareceram juntas em algumas iniciativas, ao passo que outras inciativas estiveram concentram em apenas um dos pontos. Observou-se que as iniciativas identificadas carecem de clareza quanto seus encaminhamentos práticos, e que as políticas públicas voltadas ao acesso à Internet devem ser pautadas na inclusão digital, tendo como focos o letramento digital e a emancipação digital.
\end{abstract}

Palavras-chave: Políticas públicas de informação. Inclusão digital. Internet. Tecnologias de informação e comunicação.

\section{Introdução}

No âmbito dos aspectos sociais e culturais das Tecnologias de Informação e Comunicação (TICs) na Ciência da Informação encontram-se os estudos relacionas à inclusão digital. No Brasil, a inclusão digital ganhou os holofotes das pesquisas, em especial, a partir da obra "Sociedade da Informação no Brasil: Livro Verde", publicada pelo Ministério da Ciência e Tecnologia em 2000. A publicação emergia da efervescência da sociedade da informação e das preocupações relacionados ao impulsionamento do Brasil para esse cenário. 
Temas como universalização do acesso à Internet, formas de conectividade e preparação de recursos humanos em educação para tecnologias foram centrais na discussão da obra (TAKAHASHI, 2000).

Passados mais de 20 anos dessa publicação, muita coisa mudou no cenário da Internet no Brasil. Se em 2001 8,6\% dos domicílios brasileiros dispunham de computador com Internet (INSTITUTO BRASILEIRO DE GEOGRAFIA E ESTATÍSTICA, 2002), em 2019, 71\% dos domicílios já dispunham de acesso à rede (COMITÊ GESTOR DA INTERNET NO BRASIL, 2020).

Apesar desses avanços quantitativamente significativos, há de se considerar que é um avanço desigual. Isso porque desde 2015 o acesso à Internet se aproxima da universalização nos domicílios das classes A e B, que em 2019 representavam 99\% e 95\%, respectivamente (COMITE GESTOR DA INTERNET NO BRASIL, 2020). Conforme dados do Comitê Gestor da Internet no Brasil (2020), 2019 foi o ano em que pela primeira vez, em proporção, metade do total das residências das classes DE passaram a estar conectadas à rede.

Diante desse panorama, é importante destacar que o direito à liberdade de opinião e expressão, abarcando a liberdade de procurar, receber e transmitir informações sem interferências é previsto na Declaração Universal dos Direitos Humanos (ORGANIZAÇÃO DAS NAÇÕES UNIDAS, 1948). Assim, a procura, o recebimento e a transmissão da informação podem ser entendidos como direitos humanos.

A United Nations Educational, Scentific and Cultural Organization (UNESCO) estabeleceu que as diferentes dimensões da informação podem ser consideradas como direitos humanos fundamentais e bens públicos globais, (UNITED NATIONS EDUCATIONAL, SCENTIFIC AND CULTURAL ORGANIZATION, 2007). A informação é diferente de outros bens. Ela pode estar disponível para vários usuários e com fins diferentes, e se torna mais valiosa na medida em que obtiver mais uso, podendo ser entendida como bem inalienável (UNITED NATIONS EDUCATIONAL, SCENTIFIC AND CULTURAL ORGANIZATION, 2007). 
$\mathrm{O}$ acesso à informação perpasse diretamente as possibilidades de desenvolvimento integral de uma comunidade no que diz respeito à atuação social, política, educacional e econômica. Sendo a informação um direito humano fundamental e um bem público, questiona-se a quem caberia a responsabilidade de assegurar os meios de acesso a esse bem.

Compreende-se que cabe ao Estado garantir o bem comum, ou seja, prover condições sociais que possibilitem o desenvolvimento integral dos membros de uma comunidade (DIAS; MATOS, 2019).

As ações do Estado podem ser manifestas por meio das políticas públicas. Nos regimes democráticos, as políticas públicas visam à ação coletiva, e a distribuição dos bens que são coletivos (SOUZA, 2006).

Para Dias e Matos (2019), políticas públicas podem ser compreendidas como os princípios, os critérios e as ações que assegurem e proporcionem a gestão do Estado na resolução de problemáticas nacionais. São as ações desenvolvidas ou não pelos governos direcionadas a estabelecer equidade social, visando a melhorias de qualidade de vida equilibrada à dignidade humana (DIAS; MATOS, 2019). Para os autores, a temática inclui tanto os assuntos do governo como os do Estado, na medida em que as políticas públicas de Estados são as de mais de um governo. Elas são ainda os programas de ações de um governo, que podem ser colocadas em prática tanto pelo próprio governo, como por entidades do terceiro setor autorizadas pelo poder público.

No encontro das Políticas Públicas com a Ciência da Informação, constroem-se as Políticas Públicas de Informação, campo que compreende a informação como bem e recursos que carece de coleta, processamento, manipulação, compartilhamento e gestão (HERNON; RELYEA, 2003). Elas tratam das dimensões administrativas, legais, científicas, culturais e tecnológicas associadas à criação, utilização e preservação da informação pública ou privada (JARDIM; SILVA; NHARRELUGA, 2009).

A informação de base tecnológica é predominante no contexto da emancipação em curso de um espaço do saber (LÉVY, 2015) e da busca pela efetivação de uma sociedade da informação. Nesse cenário, a Internet tem se 
tornado a principal forma para acesso à informação e meio de conexão entre pessoas e informações.

Sendo a rede o meio decisivo para o acesso à informação, e observadas as desigualdades de acesso a essa rede no país, questionamos: quais foram as ações empreendidas pelo Governo Federal voltadas à ampliação do acesso à Internet no Brasil nos últimos anos?

O acesso ainda não universal à Internet no contexto brasileiro foi fortemente evidenciado na crise de saúde causada pela pandemia do novo coronavírus. As atividades educacionais foram condicionadas ao acesso à Internet, e as dificuldades de acesso e a insuficiente capacitação para o uso das tecnologias se apresentaram às duas partes do processo - alunos e docentes -, atingindo de sobremodo os já inseridos num cenário de desigualdades off-line.

Assim, tem-se como objetivo geral identificar o cenário recente das ações do Governo Federal voltadas para a democratização do acesso à Internet no contexto nacional.

Para tanto, buscou-se mapear as principais políticas públicas de informação e as ações do Estado voltadas à ampliação do acesso à Internet no período de 2010 a 2019 no Brasil; compreender os aspectos voltados para a inclusão digital previstos nas políticas públicas e ações do Estado identificadas; e apontar os desafios para a consolidação das políticas públicas de informação para acesso à Internet e para a democratização do acesso à informação.

Optou-se pela pesquisa de base, com caráter descritivo e delineamentos bibliográfico e documental. Para seleção das políticas públicas e ações do Estado, adotou-se como critério as que foram definidas por meio de atos administrativos normativos ou por lei. A análise bibliográfica e documental, que tem por objetivo sistematizar os dados coletados, foi conduzida pela abordagem qualitativa.

Foram identificadas dez iniciativas do Governo Federal que dialogam com a ampliação do acesso à Internet, sendo elas: Projeto de Implantação e Manutenção das Cidades Digitais, Redes Digitais da Cidadania, Marco Civil da Internet, Amazônia Conectada, Programa Brasil Inteligente, Programa de Inovação Educação Conectada, Sistema Nacional para a Transformação Digital, 
Estratégia Brasileira para Transformação Digital (E-Digital), Políticas Públicas de Telecomunicações e Novo Marco Legal das Telecomunicações. A maioria das iniciativas apresenta dois pontos centrais: a infraestrutura para acesso à rede e a educação para o uso das tecnologias da informação e comunicação. Ambos os enfoques ainda se apresentam como desafiadores no contexto nacional, do ponto de vista de uma efetividade prática. Entende-se que as políticas públicas voltadas para inclusão digital devem ser integradas e projetadas com foco no letramento digital e na emancipação digital da população.

\section{As políticas públicas de informação e as ações do estado voltadas à ampliação do acesso à Internet}

A partir da pesquisa bibliográfica e documental foram identificadas dez ações do Governo Federal, criadas no período de 2010 a 2019, voltadas à ampliação do acesso à Internet, e que serão apresentadas a seguir. Outras ações e políticas estiveram em curso nesse período, mas foram iniciadas anteriormente ao período definido. Dessa forma, não farão parte das apresentadas a seguir.

\subsection{Programa Nacional de Banda Larga (PNBL) - 2010}

Foi instituído pelo Decreto $n^{\circ} 7.175$, de 12 de maio de 2010 e tinha por objetivo promover a utilização e o fornecimento de produtos e serviços de TIC para: massificar o acesso à conexão a banda larga, aumentar o desenvolvimento econômico e social, propiciar a inclusão digital, diminuir desigualdades sociais e das regiões, possibilitar geração de emprego e renda, aumentar as possibilidades de Governo Eletrônico, capacitar a população para uso das TICs e fazer crescer a competitividade e autonomia tecnológica do país (BRASIL, 2010).

As ações para o desenvolvimento do programa, segundo o decreto, deveriam ser fixadas pelo Ministério das Comunicações, e a promoção dos serviços de TIC caberia à Telecomunicações Brasileiras S.A - Telebrás. Já à Agência Nacional de Telecomunicações - Anatel caberia a implementação e execução da regulamentação dos serviços de telecomunicações, bem como da infraestrutura da banda larga. 
A inclusão digital foi mencionada no decreto como finalidade do fomento à difusão e ao uso das TICs, não sendo especificada pelo decreto quanto aos seus desdobramentos e ações. Em 2018, o programa foi substituído pelas Políticas Públicas de Telecomunicações, estabelecidas pelo decreto $\mathrm{n}^{\circ}$ 9.612, de 17 de dezembro de 2018.

\subsection{Projeto de Implantação e Manutenção das Cidades Digitais - 2011}

O projeto tem como objetivos

I - constituir redes digitais locais de comunicação nos municípios brasileiros; II - promover a produção e oferta de conteúdos e serviços digitais; e III - facilitar a apropriação de tecnologias da informação e da comunicação pela gestão pública local e pela população, de maneira coordenada e integrada entre esferas dos poderes públicos e da sociedade; IV - constituir, quando possível, enlaces de conexão entre os municípios e infraestrutura óptica nacional (backhaul). ${ }^{1}$ (BRASIL, 2011, p. 76; BRASIL, 2015, p. 52).

As Cidades Digitais, de acordo com a portaria, seriam implementadas, em especial: por meio de instalações de locais públicos para acesso livre e gratuito à Internet pela população; pela qualificação e pelo apoio aos espaços públicos de uso de tecnologias digitais; pela formação e remuneração com bolsa para os agentes de inclusão digital, os quais atuariam como monitores nos espaços públicos de utilização de tecnologias digitais; e pela promoção de iniciativas de formação para o uso das tecnologias para os indivíduos digitalmente excluídos (BRASIL, 2011, 2015).

A portaria aponta a Telebrás como a responsável pela implementação da infraestrutura do programa, sendo ela também proprietária dessa infraestrutura (BRASIL, 2015). Essa, poderia efetuar parcerias com empresas de telecomunicações e provedores de acesso à Internet para expandir os acessos e qualidade dos serviços à população (BRASIL, 2015).

A responsabilidade pela gestão e manutenção do programa ficaria a cargo dos municípios atendidos, ou do Distrito Federal (BRASIL, 2015). Os municípios e as regiões administrativas do Distrito Federal seriam selecionados para participarem no projeto a partir de editais anuais (BRASIL, 2011, 2012a). 
Em janeiro de 2013, a primeira fase do programa havia selecionado 80 municípios por edital, tendo como critérios para a seleção as cidades com até 50 mil habitantes, cidades com menor índices de desenvolvimento municipal, e a indicação de servidores para a gestão e treinamento (WAMBURG, 2013).

Quanto à inclusão digital no âmbito da formação para o uso das tecnologias, a portaria de 2011 prevê a formação de pessoal, os agentes de inclusão digital, para atuação nos espaços públicas de acesso às tecnologias digitais, e a formação continuada para servidores públicos para uso das TICs como ferramentas para gestão pública e promoção da cidadania. Além disso, também aborda a promoção de inciativas de capacitação, conjuntamente com outros programas sociais do Governo Federal, para assegurar a utilização dos equipamentos por parte dos digitalmente excluídos. Assim, há um enfoque duplo para a questão da inclusão: o uso das tecnologias e a capacitação para esse uso por parte dos agentes de inclusão e servidores.

\section{3 Redes Digitais da Cidadania - 2012}

Em 2012, o Governo Federal, por meio do Ministério das Comunicações, instituiu o Programa Redes Digitais da Cidadania, o qual tem por objetivo qualificar o uso da Internet e aumentar as capacidades dos atendidos pelas políticas sociais federais definidas nos programas temáticos do Plano Plurianual 2012-2015 para o uso das TICs, tendo por finalidade reduzir as desigualdades sociais, regionais, étnico-raciais e de gênero (BRASIL, 2012b).

A implementação do programa foi estruturada a partir de quatro ações, a saber:

I - integração das políticas de inclusão digital com as políticas sociais do Governo Federal; II - formalização de parcerias com governos estaduais, integrando esforços e ações no âmbito da inclusão sócio-digital nos municípios; III - articulação de processos formativos e ações em rede, alinhando as políticas municipais, estaduais, distrital e federal de inclusão digital; e IV - financiamento de projetos e programas de instituições públicas e de entidades privadas sem fins lucrativos que aderirem ao Programa Redes Digitais da Cidadania. (BRASIL, 2012b, p. 52). 
As responsabilidades de gestão e implementação do programa cabiam à Secretaria de Inclusão Digital do Ministério das Comunicações existente até então.

A portaria que institui o programa aponta que a execução dele deveria ser prioritariamente realizada por universidades públicas federais ou estaduais, institutos federais, empresas estatais dependentes, ou por entidades responsáveis pelo programa. Além disso, a implementação e execução do programa deveria priorizar regiões e comunidades com menores índices de desenvolvimento social e econômico, bem como aquelas com acesso à Internet deficitário (BRASIL, 2012b). O programa também admite para sua gestão e implementação parcerias com instituições privadas sem fins lucrativos.

A abordagem da inclusão digital no programa relaciona-se a intenção de integrar as políticas de inclusão digital às políticas sociais do Governo Federal (BRASIL, 2012b).

\section{4 Marco Civil da Internet - 2014}

A Lei $\mathrm{N}^{\circ}$ 12.965, de 23 de abril de 2014, conhecida como o Marco Civil da Internet, determina princípios, garantias, direitos e deveres relacionados à utilização da Internet no país. Ela também aponta os direcionamentos de atuação para a União, Estados, Distrito Federal e municípios em relação ao tema.

O marco aponta que a disciplina do uso na Internet no Brasil está pautada no respeito à liberdade de expressão, na compreensão da rede em escala global, nos direitos humanos e no exercício da cidadania digital, na diversidade e colaboração, na livre iniciativa e nos direitos do consumidor e na função social da rede (BRASIL, 2014a).

Disciplinar a Internet no Brasil tem entre os seus objetivos a intenção de promoção de que o acesso à Internet é direito de todos (BRASIL, 2014a). Dentre os direitos e garantias dos usuários da rede, a lei reconhece que o acesso à Internet é indispensável para o exercício da cidadania. Ela aponta que cabe ao poder público a promoção de ações voltadas para a capacitação do uso da Internet, e que a educação pública deve incluir, em todos os níveis, a habilitação 
“[...] para o uso seguro, consciente e responsável da internet como ferramenta para o exercício da cidadania, a promoção da cultura e o desenvolvimento tecnológico" (BRASIL, 2014a, p. 3). As ações de incentivo à cultura digital e a promoção do caráter social da Internet devem proporcionar a inclusão digital, e a diminuição de desigualdades no acesso e uso das TICs, em especial, considerando as diferentes regiões do país.

Ainda sobre a inclusão digital, a lei estabelece que o poder público, em parceria com provedores de conexão e sociedade civil, devem prover formação e orientar as boas práticas para a inclusão digital de crianças e adolescentes (BRASIL, 2014a).

Análise do Marco Civil da Internet, referente aos anos 2014 e 2015, realizada pela Artigo 19 (2015), aponta que a lei condiciona o exercício pleno da cidadania ao acesso à Internet. Nesse sentido, a Artigo 19 (2015) ressalta a essencialidade do acesso à Internet prevista na lei. A oficialização dessa compreensão poderia assegurar a universalização do acesso ao serviço no país (ARTIGO 19).

\subsection{Amazônia Conectada - 2015}

O Projeto Amazônia Conectada visa ampliar a infraestrutura de comunicações na região amazônica, bem como contribuir para as ações do Governo Federal em prol do PNLB - ainda existente à época de criação do projeto - na mesma região (MINISTÉRIO DA DEFESA; MINISTÉRIO DAS COMUNICAÇÕES; MINISTÉRIO DA CIÊNCIA, TECNOLOGIA E INOVAÇÃO, 2015).

Por meio de implantação de infovias de cabos subfluviais, o projeta tem por objetivo dar apoio às políticas de inclusão digital; aumentar e melhorar as comunicações do âmbito militar; garantir a eficiência e a segurança relacionadas à conectividade, influenciando e aperfeiçoando as práticas de pesquisa e educação; colaborar com a interiorização das políticas públicas federais e estaduais; dar suporte ao desenvolvimento tecnológico e a inovação bem como aumentar a competitividade e autonomia da indústria nacional; e auxiliar no monitoramento ambiental (MINISTÉRIO DA DEFESA; MINISTÉRIO DAS 
COMUNICAÇÕES; MINISTÉRIO DA CIÊNCIA, TECNOLOGIA E INOVAÇÃO, 2015).

O Ministério da Defesa é o responsável pela coordenação geral do projeto. Ao Comando do Exército cabe a coordenação do Comitê Gestor do Projeto Amazônia Conectadas, o qual tem entre suas atribuições a proposição de políticas de uso dos serviços a serem implementados (MINISTÉRIO DA DEFESA; MINISTÉRIO DAS COMUNICAÇÕES; MINISTÉRIO DA CIÊNCIA, TECNOLOGIA E INOVAÇÃO, 2015). Apesar do projeto datar de 2015, apenas em 2018 foi aprovado o Regimento Interno do Comitê Gestor do Projeto Amazônia Conectada, por meio da publicação da Portaria Normativa $\mathrm{N}^{\circ}$ 5/MD, de 16 de fevereiro de 2018.

Ao tratar da inclusão digital, o projeto menciona apenas o objetivo de dar apoio às políticas de inclusão digital. Nota-se que a centralidade do projeto é a implementação de infraestruturas para acesso à rede.

\subsection{Programa Brasil Inteligente - 2016}

A finalidade do programa era a busca pela universalização do acesso à Internet do Brasil. Dentre os objetivos estabelecidos pelo programa, pode-se destacar: o aumento das redes em fibra ótica, a expansão delas nas áreas urbanas, o aumento da cobertura da banda larga móvel em áreas rurais, o provimento de acesso à Internet em órgãos públicos, em especial nos das áreas de educação e saúde. Além disso, o programa tinha como objetivo a promoção da pesquisa e inovação em tecnologias móveis 5G, o incentivo do desenvolvimento e utilização de tecnologias nacionais de Internet das coisas, a capacitação de profissionais das áreas de TIC, a disponibilização de satélites em banda larga para finalidades militares, e a expansão das redes de fibra ótica na região amazônica (BRASIL, 2016).

O decreto que institui o programa determina que $60 \%$ dos municípios atendidos pela expansão de fibra ótica devem ser das áreas de atuação da Superintendência do Desenvolvimento da Amazônia (Sudam) e da Superintendência do Desenvolvimento do Nordeste (Sudene). 
O Programa Brasil Inteligente foi tido como uma versão nova do PNBL, e tinha como prioridade a implantação de Internet de alta velocidade nas escolas públicas urbanas e rurais do país (CRAIDE, 2016). Além disso, o programa também visava levar conexão à Internet por fibra ótica às unidades da terceira fase do Programa Minha Casa, Minha Vida, conforme aponta Craide (2016).

Apesar de não se mencionar diretamente a inclusão digital, entende-se que o programa aborda a temática ao ter em seu escopo uma perspectiva mais estrutural, que visava ao fornecimento de infraestrutura para o acesso à Internet. Todavia, não apresentava as questões relativas à educação para o uso das tecnologias. Em 2018, pelo Decreto $n^{\circ}$ 9.612, que dispõe sobre Políticas Públicas de Telecomunicações, o programa foi revogado.

\subsection{Programa de Inovação Educação Conectada - 2017}

A partir do estabelecido nos incisos I e VIII do Art. 24 do Marco Civil da Internet (Lei no 12.965, de 23 de abril de 2014) quanto às diretrizes para a União, Estados, Distrito Federal e municípios para o desenvolvimento na Internet no país, o programa tem por objetivo dar apoio à universalização do acesso à Internet em velocidade alta e dar suporte ao uso pedagógico das tecnologias digitais no âmbito da educação básica (BRASIL, 2017). Ele foi proposto em consonância com o Plano Nacional da Educação (PNE), aprovado pela Lei $\mathrm{N}^{\circ} 13.005$, de 25 de junho de 2014, o qual em seu artigo 7.15 propõe como estratégia:

[...] universalizar, até o quinto ano de vigência deste PNE, o acesso à rede mundial de computadores em banda larga de alta velocidade e triplicar, até o final da década, a relação computador/aluno (a) nas escolas da rede pública de educação básica, promovendo a utilização pedagógica das tecnologias da informação e da comunicação. (BRASIL, 2014b, p. 4).

A reunião de esforços entre as esferas públicas, escolas, empresas e sociedade civil para garantir a inclusão de tecnologias com objetivos pedagógicos na educação básica das escolas públicas está entre os objetivos do programa. Ele ainda se propõe a estar articulados com outros programas 
apoiados pelo Governo Federal vinculados à inovação e tecnologias educacionais (BRASIL, 2017).

Dentre os princípios norteadores do programa, pode-se destacar: a igualdade de condições para uso das tecnologias com fins pedagógicos para as escolas públicas de educação básica; a autonomia para adoção das tecnologias por parte dos professores; o acesso à Internet em condições adequadas (qualidade e velocidade) para uso pedagógico; o aumento dos acessos aos recursos educacionais digitais; e o estimulo à formação de educadores para o uso de tecnologias (BRASIL, 2017).

Para o cumprimento do plano são estabelecidas algumas ações, das quais podem-se destacar: o apoio técnico e financeiro para a contratação de serviço para acesso à Internet, provimento de infraestrutura para que as escolas recebam sinal da Internet, aquisição de dispositivos eletrônicos, recursos educacionais ou licenças. No âmbito na formação de professores, o programa visa ofertas cursos para os docentes para uso das tecnologias em sala de aula, e cursos para formar articuladores para apoiar o desenvolvimento da política (BRASIL, 2017).

O programa visa publicar parâmetros para orientar a contratação de serviços para o acesso à Internet e para equipamentos para uso da rede, e referenciais acerca das condições para a distribuição de sinal de Internet e modelos para a utilização pedagógica das tecnologias (BRASIL, 2017).

Estão diretamente envolvidos no cumprimento da política o Ministério da Educação, o Comitê Consultivo do Programa de Inovação Educação Conectada, o Ministério da Ciência, Tecnologia, Inovações e Comunicações e o Banco Nacional de Desenvolvimento Econômico e Social - BNDES (BRASIL, 2017).

O programa é apontado no Decreto $n^{\circ} 9.204$, de 23 de novembro de 2017, como complementar as outras políticas de ampliação do acesso à Internet, sejam elas nacionais, estaduais, distritais ou municipais, ao passo que a adesão ao programa não acarreta o encerramento ou substituição de outras políticas.

Segundo o Ministério da Educação (201-), o programa foi elaborado levanto em consideração quatro dimensões, a saber: visão, formação, recursos educacionais digitais e infraestrutura. Essas dimensões são complementares, e 
precisam estar em equilíbrio para que o uso das tecnologias digitais resulte em efeitos positivos na educação.

A inclusão digital é abordada nas competências do Ministério da Ciência, Tecnologia, Inovações e Comunicações, quanto à necessidade do órgão de provimento de infraestrutura para inclusão digital. As preocupações expostas no decreto quanto à formação para uso das tecnologias estão mais direcionadas aos professores, e aos articuladores de apoio à implementação da política.

\subsection{Sistema Nacional para a Transformação Digital, Estratégia Brasileira para Transformação Digital (E-Digital) - 2018}

A Estratégia Brasileira para Transformação Digital (E-Digital) compõe o Sistema Nacional para a Transformação digital (SinDigital). A E-Digital está fundamentada em eixos habilitadores e de transformação digital. Os eixos habilitadores “[...] visam criar um ambiente propício para o desenvolvimento da transformação digital da economia brasileira, com iniciativas essenciais para alavancar a digitalização" (BRASIL, 2018c, p.9). Eles reúnem as questões pertinentes à infraestrutura e acesso às TICs, pesquisa, inovação, confiança no ambiente digital, educação e capacitação profissional e ao fortalecimento da presença brasileira quanto aos temas digitais no ambiente internacional. Já os eixos de transformação digital concentram-se na transformação digital da economia e da cidadania e transformação digital do Governo (BRASIL, 2018a).

Os objetivos a serem alcançados dentro do escopo de infraestrutura são a disponibilização de redes de alta capacidade para todos os municípios brasileiros, a expansão da banda larga fixa e móvel para as áreas rurais e urbanas, e a disseminação de ações para a inclusão digital (BRASIL, 2018a).

No que tange à educação e à capacitação profissional, o decreto estabelece que a E-Digital visa disponibilizar banda larga e acesso às tecnologias digitais para escolas públicas urbanas e rurais, bem como incluir as tecnologias digitais nas práticas educacionais, promovendo o desenvolvimento do pensamento computacional como competência nos alunos. Além disso, propõe reforçar as disciplinas das áreas específicas para a formação para a 
atuação na economia digital, e aprimorar a formação inicial e continuado dos docentes para o uso das tecnologias digitais em sala de aula (BRASIL, 2018a).

A E-digital trata da inclusão digital como uma das metas a serem alcançadas pela proposta. Nota-se que o sistema visa abarcar tanto o desenvolvimento de infraestrutura de acesso à Internet e às TICs, bem como trata da educação e capacitação profissional para o mundo digital.

\subsection{Políticas Públicas de Telecomunicações - 2018}

O decreto estabelece os objetivos gerais das Políticas Públicas de Telecomunicações, dentre os quais destaca-se a promoção do acesso às telecomunicações em condições econômicas que permitam o uso dos serviços, de forma a aumentar o acesso à banda larga fixa e móvel, em especial em locais onde a oferta seja inadequada. As políticas também visam promover a inclusão digital, com foco na garantia do acesso às redes de telecomunicações e aos sistemas e serviços das TICs, considerando para tanto as desigualdades sociais e regionais (BRASIL, 2018b).

Quanto às políticas relacionados ao desenvolvimento tecnológico das telecomunicações, o decreto aponta que elas objetivam estimular o desenvolvimento e a pesquisa de tecnologias para o atendimento das políticas públicas de telecomunicações, utilizando para isso, de forma prioritária, os recursos do Fundo para o Desenvolvimento Tecnológico das Telecomunicações (FUNTTEL) e de outros projetos. Além disso, elas objetivam incentivar a competitividade nacional do setor de telecomunicações, incentivar as instituições de pesquisa para desenvolvimento de tecnologias de telecomunicações e promover a inserção de entidades privadas e de pesquisadores brasileiros no cenário internacional de discussão sobre padrões tecnológicos (BRASIL, 2018b).

As políticas de inclusão digital previstas no decreto têm o objetivo de incentivar e implantar tanto a infraestrutura como os serviços, sistemas e aplicações baseados nas TICs, visando ao atendimento às populações de locais remotos, lugares de prestação de serviços inadequados, ou que estão em estado 
de vulnerabilidade social. Além disso, objetivam dar apoio a implementação dos serviços de governo eletrônico, relacionados à transparência pública e ao aumento da participação popular, incentivar a gestão sustentável de bens informáticos do Governo Federal e estimular a formação de servidores públicos e da população para uso das TICs como meios de promoção de melhorias dos serviços públicos (BRASIL, 2018b).

O desenvolvimento de cidades inteligentes também está previsto no decreto. Dentre as iniciativas previstas para essa ação, destacam-se a oferta de acesso à Internet para uso livre e gratuito em pontos públicos e o fomento ao empreendedorismo social e digital baseado nas TICs (BRASIL, 2018b).

\subsection{Novo Marco Legal das Telecomunicações - 2019}

O Novo Marco Legal das Telecomunicações foi sancionado pela Lei $\mathrm{n}^{\mathbf{o}} 13.879$ de 2019, com foco na possiblidade de as empresas de telefonia migrarem de modalidade de outorga de serviço de telecomunicações. A partir da lei, as empresas que antes possuíam contratos de concessão podem escolher mudar para contratos de autorização, deixando assim de permanecer sob controle do Estado.

O saldo obtido da mudança do modelo de exploração deve então ser utilizado pelas empresas em compromissos de investimento, sendo as prioridades definidas pelo Poder Executivo (BRASIL, 2019). Nos termos da Lei,

os compromissos de investimento priorizarão a implantação de infraestrutura de rede de alta capacidade de comunicação de dados em áreas sem competição adequada e a redução das desigualdades, nos termos da regulamentação da Agência. (BRASIL, 2019, p. 1).

Ou seja, os saldos têm como prioridade a ampliação da infraestrutura de Internet no país, e essa ampliação é uma contrapartida da mudança do regime de concessões para autorização. A lei não trata da inclusão digital em si, mas, ao abordar a questão da infraestrutura da Internet, tangencia a temática em sua dimensão de acesso. 


\section{Os desafios para a consolidação das políticas públicas de informação para acesso à Internet}

Endente-se que as políticas públicas de informação voltadas à ampliação do acesso à Internet identificadas carecem de integração e continuidade. Muitas delas sinalizam para intenções de inclusão digital, mas não apresentam de forma clara e consistente como esse processo ocorrerá do ponto de vista prático.

A dimensão prática dessa temática tornou-se ainda mais urgente no cenário da pandemia do novo coronavírus. Motivada por isso, a International Federation of Library Associations and Institutions (IFLA), em 2020, tem apoiado e promovido dois movimentos importantes relacionados à atuação das bibliotecas do mundo todo em prol do enfrentamento da exclusão digital (INTERNATIONAL FEDERATION OF LIBRARY ASSOCIATIONS AND INSTITUTIONS, 2020). O Libraries in Response: Every Community Connected é dirigido aos governantes e alerta para a necessidade de investimentos em conectividade mais ampliada, para que as bibliotecas a utilizem em benefício de suas comunidades (INTERNATIONAL FEDERATION OF LIBRARY ASSOCIATIONS AND INSTITUTIONS, 2020). Já o Library Pledge on Promoting Digital Inclusion é um chamamento para que as bibliotecas do mundo todo assumam um compromisso de fazer tudo que estiver ao alcance delas para promover a inclusão digital (INTERNATIONAL FEDERATION OF LIBRARY ASSOCIATIONS AND INSTITUTIONS, 2020).

Considera-se que a inclusão digital trabalhada pelas políticas públicas deve levar em conta duas dimensões essenciais: o acesso às TICs e a educação para o uso delas. Nesse sentido, como apontam Kerbauy e Santos (2012), é indispensável que tais iniciativas sejam pautadas no letramento digital, a fim de se superar a perspectiva da alfabetização digital. Isso porque, enquanto o olhar da alfabetização digital está relacionado à recepção de informações no contexto on-line, o letramento digital volta-se para o desenvolvimento da postura ativa e autônoma do indivíduo na rede. 
Para Kerbauy e Santos (2012), a inclusão digital, como possibilitadora de uma ação para cidadania, requer múltiplas dimensões de observações, de forma que não é algo a ser solucionado por uma única política pública. Para as autoras, se faz necessária a construção de programas que integrem várias políticas públicas que tenham os mesmos objetivos de proporcionar a inclusão digital, e que tais políticas caminhem rumo à educação para uma nova sociedade.

Nesse sentido, Amadeu (2008) apresenta a inclusão como um processo, dando a ela um caráter de ação continuada e prolongada. Para ele, esse processo deve considerar quatro principais assimetrias no uso das redes, a saber: o acesso à banda larga, o conhecimento da língua inglesa, a bagagem cultural e as habilidades tecnológicas e os saberes técnicos. As três últimas dimensões relacionam-se diretamente com a educação dos sujeitos para rede, revelando assim indissociabilidade da educação e da inclusão digital.

Amadeu (2008), com base em Schwartz (2006), aponta o conceito de emancipação digital como alternativa para o enfrentamento da exclusão digital. Para Schwartz (2006, p.128), a emancipação digital pode ser vista "[...]como forma de potencializar os resultados obtidos pelos projetos tradicionais de inclusão digital ou mesmo para redesenhá-los”. De acordo com o autor, os processos de emancipação digital têm a sociedade do conhecimento como horizonte, e o acesso como um dos elos da produção de informação. Nesse cenário, é necessário que os indivíduos tenham controle dos processos produtivos de conteúdos digitais. A emancipação ocorre no momento que os sujeitos conseguem agir de forma individual ou coletiva em função do desenvolvimento humano (SCHWARTZ, 2006). Assim, considera-se que as políticas públicas de informação para acesso à Internet devem ser pautadas na perspectiva de emancipação dos sujeitos para o uso das tecnologias digitais.

\section{Considerações finais}

A pesquisa é um primeiro estágio para a compreensão da atuação do Estado em prol do acesso à Internet, pois teve como objetivo principal identificar o cenário 
recente das ações voltadas para a democratização do acesso à rede no contexto nacional.

Diante da manutenção do foco em atender aos objetivos propostos, não se teve como pretensão avaliar as ações identificadas a partir das metodologias de análise de políticas públicas. Assim, vê-se nisso a oportunidade de continuidade e aprofundamento da investigação em trabalhos futuros.

Foram identificadas dez inciativas principais, desenvolvidas no período de 2010 a 2019, voltadas à ampliação do acesso à Internet no Brasil desenvolvidas pelo Governo Federal. Dentre elas, pode-se destacar o Marco Civil da Internet, que estabeleceu o acesso à Internet como um direito de todos, e o poder público como responsável pela capacitação para o uso da rede, inclusive por meio da atuação da educação pública. Isso permite compreender que a inclusão digital não é dissociada da educação, muito pelo contrário, é exercida por meio das práticas educativas.

A participação na rede tem na distribuição de infraestruturas de Internet seu primeiro passo. Todavia, não é o único. Esse primeiro passo ainda é um desafio no contexto brasileiro, no qual as desigualdades territoriais, os lugares em que se vive, interferem na inclusão digital, e as desigualdades do universo off-line estão associadas as do online (ARRETCHE, 2019).

Notou-se que a inclusão digital deve ser observada por duas perspectivas: a do acesso à infraestrutura e a da educação para o uso das TICs, com enfoque no letramento digital. Além disso, as políticas públicas que abordam a inclusão digital devem tratá-la como um processo que leve à emancipação digital e que busque a autonomia dos sujeitos na sociedade informacional.

A temática está longe de ser esgotada, uma vez que as desigualdades digitais têm se mostrado cada vez mais intensificadas, sobretudo durante o contexto da pandemia da Covid-19, que sobreveio à população mundial, mas tem apresentado efeitos prevalentes no Brasil. Neste sentido, vê-se também como possibilidades de estudos futuros a investigação dos efeitos da exclusão institucional causada pela falta de acesso às TICs em populações específicas durante o contexto da pandemia. 


\section{Financiamento}

Programa de Incentivo à Pesquisa Docente (PIPED) da Fundação Escola de Sociologia e Política de São Paulo (FESPSP).

\section{Referências}

AMADEU, Sérgio. A noção de exclusão digital diante das exigências de uma cibercidadania. In: HETKOWSKI, Tânia Maria. Políticas públicas \& inclusão digital. Salvador: EDUFBA, 2008. p. 43-66.

ARRETCHE, Marta. A Geografia Digital no Brasil: um panorama das desigualdades regionais. In: COMITÊ GESTOR DA INTERNET NO BRASIL. Desigualdades digitais no espaço urbano: um estudo sobre o acesso e o uso da Internet na cidade de São Paulo. São Paulo: Comitê Gestor da Internet no Brasil, 2019. p.55-79.

ARTIGO 19. Análise do Marco Civil da Internet: 2014-2015. Londres: Artigo 19, 2015. Disponível em: https://www.article19.org/wpcontent/uploads/2015/11/An\%C3\%A1lise-do-MCI-PDF.pdf. Acesso em: 11 set. 2020 .

BRASIL. Decreto ${ }^{\circ}$ 7.175, de 12 de maio de 2010. Institui o Programa Nacional de Banda Larga - PNBL; dispõe sobre remanejamento de cargos em comissão; altera o Anexo II ao Decreto no 6.188, de 17 de agosto de 2007; altera e acresce dispositivos ao Decreto no 6.948, de 25 de agosto de 2009; e dá outras providências. Diário Oficial [da] República Federativa do Brasil: seção 1, Brasília, DF, ano 147, n. 90, p. 3, 13 maio 2010.

BRASIL. Decreto no 8.776, de 11 de maio de 2016. Institui o Programa Brasil Inteligente. Diário Oficial [da] República Federativa do Brasil: seção 1, Brasília, DF, ano 153, n. 91, p. 20, 12 maio 2016.

BRASIL. Decreto ${ }^{\circ}$ 9.204, de 23 de novembro de 2017. Institui o Programa de Inovação Educação Conectada e dá outras providências. Diário Oficial [da] República Federativa do Brasil: seção 1, Brasília, DF, ano 154, n. 255, p. 41, 24 nov. 2017.

BRASIL. Decreto ${ }^{\circ}$ 9.319, de 21 de março de 2018. Institui o Sistema Nacional para a Transformação Digital e estabelece a estrutura de governança para a implantação da Estratégia Brasileira para a Transformação Digital. Diário Oficial [da] República Federativa do Brasil: seção 1, Brasília, DF, ano 155, n. 56, p. 2, 22 mar. 2018a.

BRASIL. Decreto n 9.612, de 17 de dezembro de 2018. Dispõe sobre políticas públicas de telecomunicações. Diário Oficial [da] República Federativa do Brasil: seção 1,Brasília, DF, ano 155, n. 242, p. 38, 18 fev. 2018 b. 
BRASIL. Lei $\mathrm{n}^{\circ}$ 12.965, de 23 de abril de 2014. Estabelece princípios, garantias, direitos e deveres para o uso da Internet no Brasil. Diário Oficial [da] República Federativa do Brasil: seção 1, Brasília, DF, ano 151, n. 77, p. 1, 1 out. 2014a.

BRASIL. Lei no 13.005 , de 25 de junho de 2014. Aprova o Plano Nacional de Educação - PNE e dá outras providências. Diário Oficial [da] República Federativa do Brasil: seção 1, Brasília, DF, ano 151, n. 120, p. 1, 26 jun. $2014 b$.

BRASIL. Lei $n^{\circ} 13.879$, de 3 de outubro de 2019. Altera a Lei ${ }^{\circ}$ 9.472, de 16 de julho de 1997, para permitir a adaptação da modalidade de outorga de serviço de telecomunicações de concessão para autorização, e a Lei n ${ }^{\circ}$ 9.998, de 17 de agosto de 2000, e revoga dispositivos da Lei no 9.472, de 16 de julho de 1997.

Diário Oficial [da] República Federativa do Brasil: seção 1, Brasília, DF, ano 156, n. 193, p. 1, 4 out. 2019.

BRASIL. Ministério da Ciência, Tecnologia, Inovações e Comunicações. Estratégia brasileira para a transformação digital - E-Digital. Brasília, DF: Ministério da Ciência, Tecnologia, Inovações e Comunicações, 2018c.

BRASIL. Ministério das Comunicações. Portaria $\mathbf{n}^{\mathbf{0}}$ 186, de 28 de março de 2012. Altera a Portaria $n^{\circ} 376$, de 19 de agosto de 2011, referente à instituição do Projeto de Implantação e Manutenção das Cidades Digitais. Brasília, DF: Ministério das Comunicações, 2012a.

BRASIL. Ministério das Comunicações. Portaria n⿳0 359, de 2 de agosto de 2012. Institui o Programa Redes Digitais da Cidadania com o objetivo de desenvolver e coordenar ações que possibilitem qualificar o uso da internet e ampliar as capacidades para uso das Tecnologias da Informação e Comunicação - TIC dos públicos das políticas sociais do Governo Federal, definidas nos Programas Temáticos do PPA 2012-2015. Brasília, DF: Ministério das Comunicações, $2012 b$.

BRASIL. Ministério das Comunicações. Portaria no 376 , de 19 de agosto de 2011. Institui o Projeto de Implantação e Manutenção das Cidades Digitais. Brasília, DF: Ministério das Comunicações, 2011.

BRASIL. Ministério das Comunicações. Portaria $n^{\circ}$ 4.699, de 14 de outubro de 2015. Altera a Portaria $n^{\circ} 376$, de 19 de agosto de 2011, referente à instituição do Projeto de Implantação e Manutenção das Cidades Digitais. Brasília, DF: Ministério das Comunicações, 2015.

COMITÊ GESTOR DA INTERNET NO BRASIL. TIC Domicílios: pesquisa sobre o uso das tecnologias e informação e comunicação nos domicílios brasileiros - 2019. São Paulo: CGI, 2020. 
CRAIDE, Sabrina. Governo quer levar internet rápida para escolas públicas. Agência Brasil, Brasília, DF, 6 abr. 2016. Disponível em:

https://agenciabrasil.ebc.com.br/geral/noticia/2016-04/governo-quer-levarinternet-rapida-para-escolas-publicas. Acesso em: 08 ago. 2020.

DIAS, Reinaldo; MATOS, Fernanda. Políticas públicas: princípios, propósitos e processos. São Paulo: Atlas, 2019.

INTERNATIONAL FEDERATION OF LIBRARY ASSOCIATIONS AND INSTITUTIONS. Every Community Connected: a call to action, a pledge to engage. 2020.

HERNON, Peter.; RELYEA, Harold. Information Policy. In: DRAKE, Mirian (ed.). Encyclopedia of library and information science. 2. ed. New York: Marcel Dekker, 2003. v. 2.

INSTITUTO BRASILEIRO DE GEOGRAFIA E ESTATÍSTICA. Pesquisa acional por amostra de domicílios: síntese de indicadores 2001. Rio de Janeiro: IBGE, 2002.

JARDIM, José Maria; SILVA, Sérgio Conde de Albite; NHARRELUGA, Rafael Simone. Análise de políticas públicas: uma abordagem em direção às políticas públicas de informação. Perspectivas em Ciência da Informação, Belo Horizonte, v. 14, n. 1, p. 2-22, abr. 2009.

KERBAUY, Maria Terese Miceli; SANTOS, Vanessa Matos dos. Cidadania digital: entre o acesso e a participação. In: LIMA, M. C.; ANDRADE, T. N. (org.). Desafios da inclusão digital: teoria, educação e políticas públicas. São Paulo: Hucitec, c2012. p. 17-42.

LÉVY, Pierre. A inteligência coletiva: por uma antropologia do ciberespaço. São Paulo: Folha de São Paulo, 2015.

MINISTÉRIO DA DEFESA; MINISTÉRIO DAS COMUNICAÇÕES; MINISTÉRIO DA CIÊNCIA, TECNOLOGIA E INOVAÇÃO. Portaria interministerial $n^{0}$ 586, de 22 de julho de 2015. Institui o Projeto Amazônia Conectada e dá outras providências. Brasília, DF: Ministério da Defesa, 2015.

MINISTÉRIO DA DEFESA. Portaria normativa $\mathbf{n}^{0}$ 5/MD, de 16 de fevereiro de 2018. Aprova o Regimento Interno do Comitê Gestor do Projeto Amazônia Conectada. Brasília, DF: Ministério da Defesa, 2018.

MINISTÉRIO DA EDUCAÇÃO. Programa de inovação educação conectada. Brasília, DF: MEC, [201-].

SCHWARTZ, Gilson. Educar para emancipação digital. In: SANTOS, Emerson. (org.). Reescrevendo a educação: propostas para um Brasil melhor. São Paulo. Scipione, 2006. p. 125-135. 
SOUZA, Celina. Políticas públicas: uma revisão de literatura. Sociologias, Porto Alegre, ano 8, n. 16, p. 20-45, jul./dez. 2006.

\title{
ORGANIZAÇÕES DAS NAÇÕES UNIDAS (ONU). Declaração Universal dos Direitos Humanos. Paris: ONU, 1948.
}

TAKAHASHI, Tadao (org.). Sociedade da informação no Brasil: livro verde. Brasília, DF: Ministério da Ciência e Tecnologia, 2000.

UNITED NATIONS EDUCATIONAL, SCENTIFIC AND CULTURAL ORGANIZATION. Building national information policies:

experiences in Latin America. Kingston: UNESCO, 2007.

WAMBURG, Jorge. Programa Cidades Digitais começa a ser implantado em 80 municípios. Agência Brasil. Brasília, DF, 29 jan. 2013.

\section{Information public policies: a look at Internet access and digital inclusion in the Brazilian scenario}

\begin{abstract}
It aims to identify the recent scenario of Federal Government actions aimed at democratizing Internet access in the national context. It was chosen as methodological procedures by basic research, of descriptive character and bibliographic and documentary design, considering the actions undertaken by the Federal Government from 2010 to 2019 . The analysis was conducted by the qualitative approach. Ten main initiatives undertaken that dialogue with the expansion of Internet access were identified, the oldest one being the National Broadband Program and the most recent being Telecommunications Public Policies and the New Legal Framework for Telecommunications. The main points about digital inclusion observed in the initiatives identified are the infrastructure for accessing the Internet and education for the use of information and communication technologies. These perspectives appeared together in some initiative, while other initiatives were concentrated on only one of the points. It was observed that the initiatives identified lack clarity as to their practical directions, and that public policies aimed at Internet access must be guided by digital inclusion, focusing on digital literacy and digital emancipation.
\end{abstract}

Keywords: Information public policies. Digital inclusion. Internet. Information and communication technologies.

Recebido: 11/12/2020

Aceito: 17/05/2021

\section{Declaração de autoria}

Concepção e elaboração do estudo: Angela Halen Claro Franco

Coleta de dados: Angela Halen Claro Franco 
Análise e interpretação de dados: Angela Halen Claro Franco

Redação: Angela Halen Claro Franco

Revisão crítica do manuscrito: Angela Halen Claro Franco

\section{Como citar}

FRANCO, Angela Halen Claro. Políticas públicas de informação: um olhar para o acesso à Internet e para a inclusão digital no cenário brasileiro. Em Questão, Porto Alegre, v. 27, n.4, p 61-83, 2021. Doi: http://dx.doi.org/10.19132/18085245274.61-83

\footnotetext{
${ }^{1}$ Inciso IV dado pela Redação da Portaria No 4.699, de 14 de outubro de 2015, que altera a Portaria no 376, de 19 de agosto de 2011, referente à instituição do Projeto de Implantação e Manutenção das Cidades Digitais.
} 